J. Lake Sci. (湖泊科学), $2006, \mathbf{1 8}(6): 579-584$

http:// www. jlakes. org. E-mail: jlakes@ niglas. ac.cn

(c) 2006 by Journal of Lake Sciences

\title{
滇池东北岸生态修复区的环境效应——II. 污染净化效应”
}

\author{
潘继征, 李文朝, 陈开宁 \\ (中国科学院南京地理与湖泊研究所,南京 210008)
}

\begin{abstract}
摘 要: 研究了滇池东北沿岸带生态修复区去除水体中污染物和营养盐的能力. 对修复区在重富营养水体迎风岸、无陆 源污染情况下通过收获水生植物和促进悬浮物沉降方式去除的湖泊内源污染物质进行了定量的监测分析. 结果显示, 修 复区对外来的悬浮物质具有强大的凝集、固定作用,植被区内每平方米湖面平均年沉积量达 $118.9 \mathrm{~kg}$ (干重), 其中的氮、 磷、有机碳含量分别达 $120 \mathrm{~g} /\left(\mathrm{m}^{2} \cdot \mathrm{a}\right) 、 70 \mathrm{~g} /\left(\mathrm{m}^{2} \cdot \mathrm{a}\right) 、 1080 \mathrm{~g} /\left(\mathrm{m}^{2} \cdot \mathrm{a}\right)$; 修复区内的底质环境得到明显改善,表层沉积物 中氮和有机碳含量比原初提高了 4 倍以上; 修复区内水生植被具有极高的生产能力,仅 2002 年修复区就收割打捞水生植 物 $113 \mathrm{t}$ (干重), 由此去除氮、磷分别为 $30.0 \mathrm{~g} /\left(\mathrm{m}^{2} \cdot \mathrm{a}\right)$ 和 $4.8 \mathrm{~g} /\left(\mathrm{m}^{2} \cdot \mathrm{a}\right)$. 因此, 沿岸带生态修复完全可以作为湖泊内 源污染净化的一项工程措施在滇池东北沿岸或类似重污染水体推广应用.
\end{abstract}

关键词 : 滇池;沿岸带;生态修复;污染净化

\section{A Study on the environmental effect in the zone of restoration of aquatic plants at the northeastern Dianchi Lake: II. the effect on removing the pollutants}

\author{
PAN Jizheng, LI Wenchao \& CHEN Kaining \\ ( Nanjing Institute of Geography and Limnology, Chinese Academy of Sciences, Nanjing 210008, P. R. China )
}

\begin{abstract}
The effects of removing the pollutants by aquatic plants in the restoration zone in the northeastern of Dianchi Lake were investigated in this paper. The volume of the pollutants removed from the lake by the aquatic plant harvesting and the sedimention had also been estimated. The result showed that the restoration zone had a remarkable accelerative effect on silting-up of the restoration. In the whole restoration zone, the average sedimentation flux was $118.9 \mathrm{~kg} /\left(\mathrm{m}^{2} \cdot \mathrm{a}\right)$. There fore it means about $120 \mathrm{~g} /\left(\mathrm{m}^{2} \cdot \mathrm{a}\right) \mathrm{TN}, 70 \mathrm{~g} /\left(\mathrm{m}^{2} \cdot \mathrm{a}\right) \mathrm{TP}$ and $1080 \mathrm{~g} /\left(\mathrm{m}^{2} \cdot \mathrm{a}\right)$ TOC can be removed from lake. The situation of the sedimention in the zone has been improved a lot, as the concentration of TN and TOC in the surface sediment was 4 times as high as before. The amount of harvested aquatic plants was about $113000 \mathrm{~kg}$ in 2002 , which means that $30.0 \mathrm{~g} /\left(\mathrm{m}^{2} \cdot \mathrm{a}\right) \mathrm{TN}$ and $4.8 \mathrm{~g} /\left(\mathrm{m}^{2} \cdot \mathrm{a}\right) \mathrm{TP}$ were removed from lake. Therefore, it can be concluded that the restoration of aquatic plants in the littoral may be used as an effective engineering measure for lake's pollution control especially the algae bloom control at the northeastern Dianchi Lake, and in other severely polluted water bodies.
\end{abstract}

Keywords : Dianchi Lake; aquatic plants; ecological restoration; removing pollutant

沿岸带处在湖泊水体与陆地的过度,生态良好的沿岸带既是拦截净化来自陆地污染物的天然屏障, 同 时又是湖泊内源污染物质输移转化的重要场所 ${ }^{[1,2]}$. 关于水生高等植物通过吸收水体和沉积物中的营养盐 净化水质的作用, 已为国内外众多研究结果所肯定 ${ }^{[3-10]}$; 而高等水生植物强烈的促淤作用由于加速了湖泊 的衰老和消亡而通常被认为是其环境功能中最大的负面效应,但许多研究结果证明通过促淤作用,水生植 物有将湖水中的氮传输到底泥中, 使其进人地球化学循环的功能, 并可通过促进湖水中含磷物质的沉降和 防止淤积物再悬浮实现磷的沉积固定 ${ }^{[11,12]}$. 本文对滇池东北岸一个面积 $6.7 \mathrm{hm}^{2}$ 左右的 “沿岸带生态修复

* 科技部重大项目 “滇池污染治理技术研究” ( K99-05-35-01) 、中国科学院知识创新工程领域前沿项目 (CXNIGLAS - A02-04) 共同资助. 2004-06-30 收稿;2006-03-28 收修改稿. 潘继征, 男, 1975 年生, 助理研究员, Email:jzhpan@ niglas. ac.cn. 
区” ${ }^{[15]}$ 进行了周年的跟踪监测, 研究分析了修复区在没有陆源污染介人情况下, 通过悬浮物凝集沉降和水 生植物生长收割去除的湖泊内源污染负荷量,进行了定量的监测分析, 得出了惊人的结果. 证明湖泊沿岸带 生态修复是提高湖泊自净能力、削减湖泊污染源的有效手段, 可作为湖泊内源污染净化的一项工程措施在 滇池东北沿岸或类似重污染水体推广应用. 本文对这一研究结果进行初步总结和讨论, 以供参考.

\section{1 研究方法}

\section{1 修复区内外水质监测}

在生态修复区内、外共设 13 个采样点,分为五组, $1-3$ 号在芦苇 (Phragmitis communis Trin.) 群落内, 4 - 6 号在狭叶香蒲 (Typha angustifolia L.) 群落内,7 -9 号在马来眼子菜 (P. malaianus Miq) - 狐尾藻 (Myriophyllum spicatum L. ) 群落 (简称马来眼子菜群落) 内, 10 号在东方香蒲 (Typha orientalis Presl) 群落内, 11 号 在荠草 (Zizania latifolia Turcz) 群落内, 12、13 号为修复区外对照点 (图 1).2003 年 3 月 - 11 月,每月进行一 次水质采样分析和植物群落调查, 水质分析项目为 $\mathrm{COD}_{\mathrm{Cr}} 、 \mathrm{TN} 、 \mathrm{TP}$.

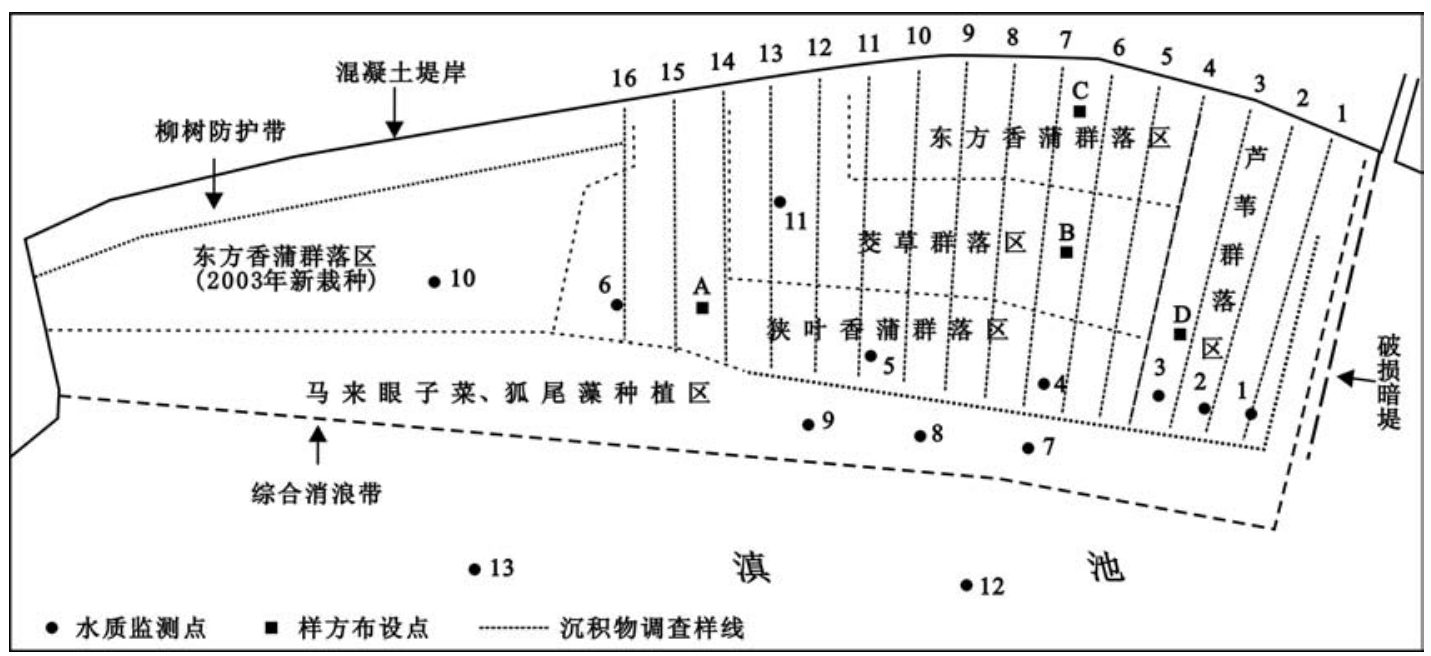

图 1 沿岸带生态修复区水生植物群落分布及样点布设

Fig. 1 Sketch of the sampling sites and distribution of. communities in the zone of ecological restoration, Dianchi Lake

\section{2 周年沉积量调查}

1.2 .1 背景状况调查 2002 年 4 月对修复区内部的沉积环境进行了全面的勘查, 当时修复区的水位较低, 出现大面积露滩. 调查中发现整个修复区的沉积物性状比较均一,都是黄色的粗沙,因此在修复区的东西部 各选取一个代表点, 用内径 $90 \mathrm{~mm}$ 的柱状沉积物采样器采集表层 $20 \mathrm{~cm}$ 的沉积物样品, 风干后分析其中 TOC、TN、TP 的百分含量;

1.2 .2 周年沉积量调查 2003 年 4 月,在修复区东部岸段在挺水植被区内,从东到西沿垂直于岸线的方向, 每隔 $20 \mathrm{~m}$, 设一条样线, 共计 16 条(图 1); 每条样线从岸边 $5 \mathrm{~m}$ 处至挺水植物边界每隔 $10 \mathrm{~m}$ 设一样点, 共计 112 个, 用内径 $90 \mathrm{~mm}$ 的柱状沉积物采样器采集沉积物样品至坚硬湖底层, 切割新生沉积层, 测量厚度, 将 所有新生沉积物进行自然干燥, 测定总重量、垃圾杂物量, 分析其中 TOC、TN、TP 的百分含量.

\section{3 水生植物周年生长量与 N、P 吸收量的观测分析}

根据修复区内群落的分布状况, 设定 4 个 $5 \mathrm{~m} \times 5 \mathrm{~m}$ 的样方, 其中样方 $\mathrm{A}$ 在狭叶香蒲群落区, $\mathrm{B}$ 在荠草 群落区, C 在东方香蒲群落区, D 在芦苇群落区, 每个月一次, 选定其中 $1 \mathrm{~m} \times 1 \mathrm{~m}$ 的植被面积, 将内部植物连 
根拔起, 洗净晾干计算其生物量 (鲜重). 另取部分完整植株在室内自然通风条件下, 干燥一个月, 测定其干 湿比.于 2003 年 3 月以及 2004 年 3 月分别对修复区内植被的水面以上部分进行收割, 统计收割量, 并分析 其中的 TOC、TN、TP 的百分含量. 由于 2003 年 7 月艾草发生 “锈病”, 为了避免其他群落受到影响, 于 2003 年 8 月对荠草群落进行收割. 以上分析方法见文献 ${ }^{[16]}$.

\section{2 研究结果}

\section{1 周年沉积量及营养组成}

岸带生态修复区建设前, 由于地处迎风岸, 风浪冲刷非常强烈, 由于波浪湖流的分选作用, 比较细的泥 沙被湖水带往深水区, 只有比较粗的中沙以上成分在湖滩上沉积下来,沉积物中的营养成分相当贫痊, TOC、TN、TP 最大只有 $0.269 \% 、 0.030 \%$ 和 $0.045 \%$, 随着岸带生态修复的进行, 修复区内的底质条件得到了 极大的改善,沉积物中的 TOC、TN、TP 含量分别比原初提高了 4.69 倍、4.17 倍和 1.41 倍.

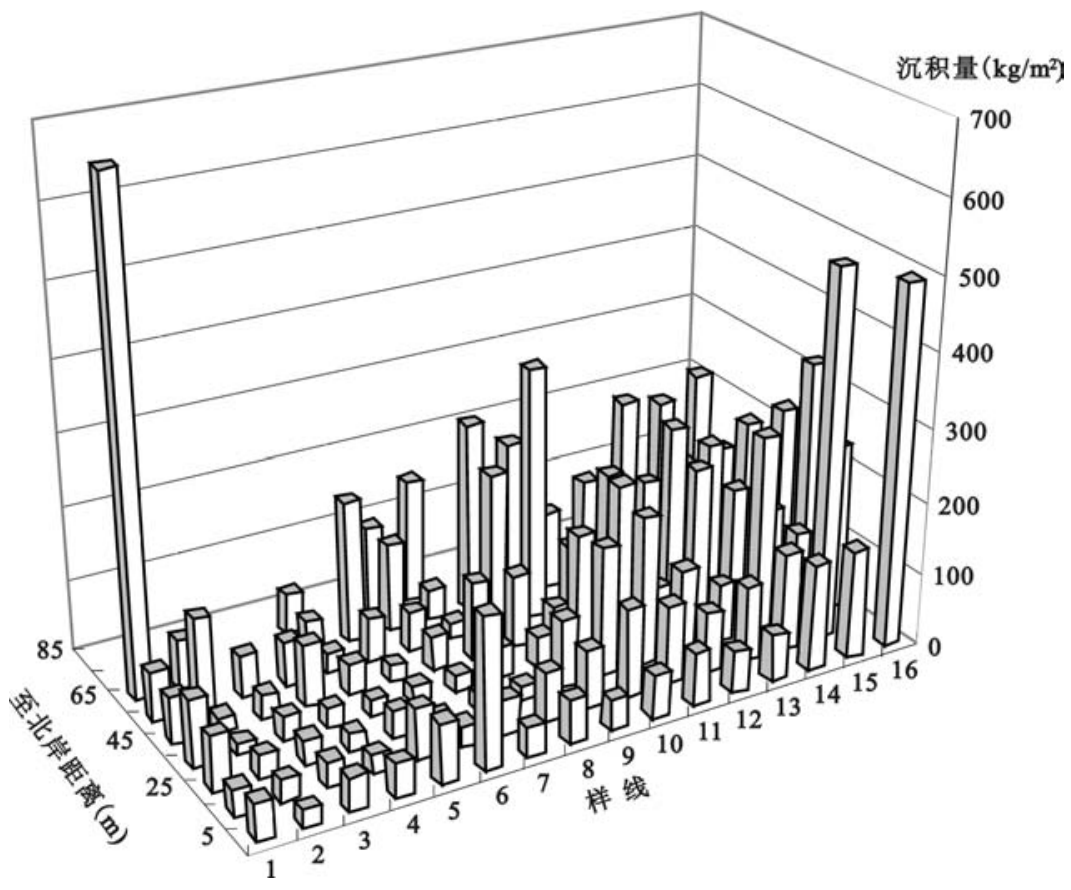

图 2 东湾生态修复区东部 2002 年 4 月 - 2003 年 4 月沉积量分布图

Fig. 2 the distribution of sedimentary amount produced from Apr. 2002 to Apr. 2003 in the east of the restoration zone

经过一周年的运行, 修复区对悬浮物表现出了十分明显的凝集、固定效果, 平均沉积量达到 $118.9 \mathrm{~kg} /$ $\mathrm{m}^{2}$, 在局部地区甚至超过了 $600 \mathrm{~kg} / \mathrm{m}^{2}$, 在挺水植被区的东南和西北角分别出现了两个峰值. 最高达到了 $682.5 \mathrm{~kg} / \mathrm{m}^{2}$. 修复区的沉积量分布整体呈现出了明显的西高东低的现象 (图 2).

\section{2 修复区内的植物生长}

生态修复区内的植物群落以人工移植的挺水植物为主, 具有极高的生产能力, 其生物量的峰值主要出 现在 7-8 月, 其中荠草可以达到 $72 \mathrm{~kg} / \mathrm{m}^{2}$ (鲜重), 而东方香蒲和狭叶香蒲也分别可以达到 $30 \mathrm{~kg} / \mathrm{m}^{2}$ 和 26 $\mathrm{kg} / \mathrm{m}^{2}$ (鲜重), 荠草、芦苇和狭叶香蒲群落属于一年生草本植物, 在每年的秋冬季节都要枯落调亡, 进人 11 月份生物量迅速下降,而移自异龙湖的东方香蒲则属于多年生草本植物,在滇池可以安全越冬,其生物量的 


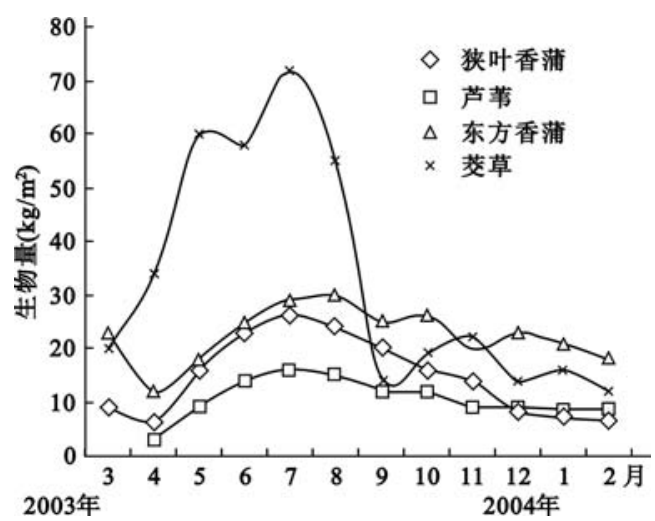

图 3 修复区内各群落生物量年度变化

(2003 年 3 月和 2004 年 3 月所有群落全部收割, 2003 年 8 月只收割萃草群落)

Fig. 3 The monthly variations of average productivity of aquatic plants in the restoration zone

变化也相对较小 (图 3 ).

对挺水植物的营养组成分析结果显示, 作为植 物收获的主体,东方香蒲和狭叶香蒲的茎叶中氮、磷 含量较高, 其中总氮在 $1.3 \%$ 左右, 总磷也都超过了 $0.2 \%$; 芦苇的成分主要是有机碳占了将近一半的干 重, 氮、磷含量较低, 只有前者的 $1 / 3$ 左右; 而艾草总 体的营养水平最低约占香蒲类的 $1 / 2$ 左右 (表 1 ).

\section{3 修复区内外水质变化}

修复区内 $\mathrm{COD}_{\mathrm{Cr}} 、 \mathrm{TN} 、 \mathrm{TP}$ 含量的季节变化十分 明显, $\mathrm{COD}_{\mathrm{Cr}} 3-6$ 月份低于对照区, 8-10月份呈现 出明显的上升趋势, 在 10 月份达到最大值 915.87 $\mathrm{mg} / \mathrm{L}$, 是对照区的 7.7 倍; TN、TP 常年高于对照区, 并分别在 $9 、 10$ 月份出现了一个极高的峰值 ( TN $31.1 \mathrm{mg} / \mathrm{L}$, TP $1.44 \mathrm{mg} / \mathrm{L}$ ), 是对照区的 7.4 倍和 7.7 倍(图 4).

表 1 修复区内挺水植物 (干重) 的营养组成

Tab. 1 The nutrient content of emergent plant in the restoration zone

\begin{tabular}{cccc}
\hline 样品 & TOC $(\%)$ & TN $(\%)$ & TP $(\%)$ \\
\hline 东方香蒲根 & 35.067 & 1.063 & 0.345 \\
东方香蒲茎叶 & 42.545 & 1.264 & 0.231 \\
荠 草 根 & 44.130 & 1.191 & 0.187 \\
萃 草 茎叶 & 15.238 & 0.882 & 0.103 \\
狭叶香蒲根 & 38.757 & 1.316 & 0.319 \\
狭叶香蒲茎叶 & 44.055 & 1.342 & 0.128 \\
芦苇 & 45.961 & 0.450 & 0.082 \\
\hline
\end{tabular}
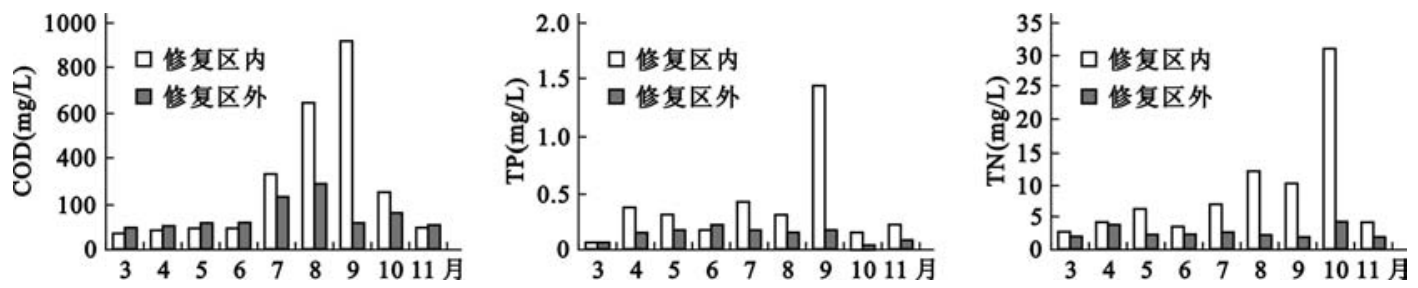

图 42003 年修复区内外水中 $\mathrm{COD}_{\mathrm{Cr}}$ 、TN 、TP 的周年变化

Fig. 4 The annual fluctuations of $\mathrm{COD}_{\mathrm{Cr}}$ TN and TP in the inside of the restoration zone and the control

\section{3 分析与讨论}

\section{1 营养负荷的沉积输出}

实验结果表明,生态修复区建成后改善了沿岸带的底质条件, 促进了水体中悬浮颗粒的沉降,使得大量 的污染物被固定在沉积物中,对湖泊水体的净化起到了积极的作用.

修复区内的沉积量分布从整体来说呈现出了西高东低的现象, 尤其是东北部更是明显的低于其他区域 (图 2), 这与修复区内地形状况密切相关, 由于修复区东北部地势较高,在低水位时 (一般 5-9 月), 长时间 处于露滩状态 ${ }^{[15]}$, 从而导致沉积量偏小. 同时,在周围区域沉积量平均只有 $65 \mathrm{~kg} /\left(\mathrm{m}^{2} \cdot \mathrm{a}\right)$ 的情形下, 修复 区的东南角却出现了整个修复区的最高值, 分析认为, 主要是由于修复区东边界有一破损的混凝土暗堤, 这 
一区域恰好处于暗堤尽头与露滩外界相交处,在滇池西南风主导风向下,大量的悬浮物质在此堆积,形成一 局高埂.

在垂直于岸线方向的分析中发现,由于修复区正对西南,在风浪推动力和修复区内植物阻滞力的共同 作用下, 悬浮物的最大沉降点发生在靠近挺水植被区外沿 $10 \mathrm{~m}$ 处,但沉积物中的营养物质浓度在该处却呈 现出一个低峰值 (表 2), 这说明由大湖面带来的营养物质含量较高的有机碎屑和悬浮垃圾由于比重较轻或 随波浪涌进修复区内部, 或被拦截于修复区外沿, 而比重较大的无机颗粒则大多在此处沉降, 形成高埂, 这 与现场的调查结果吻合. 同时修复区中心地带沉积物中的营养物质浓度明显低于边缘区域,两者相差在 2 倍左右, 这一方面可能是由于风浪作用, 导致大量密度较轻的有机碎屑在近岸带聚集, 这从现场观察和性状 分析都可以证明,而来自大湖面水体的污染物质在挺水植物区外沿被大量凝集固定, 从而在此形成峰值; 另 一方面, 也可能是因为中心区风浪较小、植被发育较好, 更适于周丛生物生长繁殖, 微生物的降解能力和效 率远高于边缘区域造成的.

经过统计, 修复区内每平方米湖面平均年沉积通量达 $118.9 \mathrm{~kg} / \mathrm{m}^{2}$ (干重), 修复区对氮、磷、有机碳的年 沉积去除效率分别达 $120 \mathrm{~g} /\left(\mathrm{m}^{2} \cdot \mathrm{a}\right) 、 70 \mathrm{~g} /\left(\mathrm{m}^{2} \cdot \mathrm{a}\right) 、 1080 \mathrm{~g} /\left(\mathrm{m}^{2} \cdot \mathrm{a}\right)$; 总沉积量可以达到 $5617.91 \mathrm{t}$, 其中含 氮 $5.74 \mathrm{t}$, 含磷 $3.30 \mathrm{t}$. 这些 “淤积物” 主要来自湖泊内部的污染物, 水生植物成分占这些淤积物的比重微乎 其微. 研究资料表明,水生植物残体在湖泊环境中很容易腐烂分解,周年分解失重接近 $80 \%{ }^{[17]}$. 东湾生态修 复区 $6.7 \mathrm{hm}^{2}$ 水生植被年产生植物残体约 $60 \mathrm{t}$ (年生长量按照最大生物现存量估算,除去收割量之外,并非 全部成为植物残体, 因为这些水生植物大多为宿根性多年生植物, 根系占生物量比例达到 $40 \%$ 左右), 经过 腐烂分解之后进人沉积物的残渣不超过 $12 \mathrm{t}$. 仅占年沉积总量的 $0.2 \%$.

表 2 修复区内沉积物中营养物质含量沿垂直于岸线方向的变化趋势 (单位: $\mathrm{kg} / \mathrm{m}^{2}$ )

Tab. 2 The changing of nutrient content of sediment longitudinal transport in the restoration zone

\begin{tabular}{ccccccccccc}
\hline 离岸距离 $(\mathrm{m})$ & 5 & 15 & 25 & 35 & 45 & 55 & 65 & 75 & 平均值 & 合计 $(\mathrm{t})$ \\
\hline $\mathrm{TOC}$ & 1.7 & 0.77 & 0.63 & 0.62 & 0.64 & 1.31 & 1.42 & 1.58 & 1.08 & 51.21 \\
$\mathrm{TN}$ & 0.134 & 0.096 & 0.082 & 0.075 & 0.083 & 0.144 & 0.199 & 0.159 & 0.12 & 5.74 \\
$\mathrm{TP}$ & 0.076 & 0.062 & 0.056 & 0.054 & 0.054 & 0.072 & 0.114 & 0.071 & 0.07 & 3.30 \\
$\mathrm{TOC} / \mathrm{TN}$ & 12.69 & 8.02 & 7.68 & 8.27 & 7.71 & 9.10 & 7.14 & 9.94 & 9.00 & \\
沉积量 & 102.64 & 99.26 & 100.9 & 106 & 105.2 & 120.5 & 200.56 & 116.21 & 118.90 & 5617.91 \\
\hline
\end{tabular}

\section{2 水生植物的吸收净化}

2002 年生态修复区东部 $4.7 \mathrm{hm}^{2}$ 植被区年生长水生植物 $228 \mathrm{t}$ (干重), 收割打捞植物水面以上部分 $113 \mathrm{t}$ (干 重), 收获率为 $49.6 \%$, 通过收获水生植物去除氮、磷的效率分别为 $30.0 \mathrm{~g} /\left(\mathrm{m}^{2} \cdot \mathrm{a}\right)$ 和 $4.8 \mathrm{gP} /\left(\mathrm{m}^{2} \cdot \mathrm{a}\right) .2003$ 年与 2002 年相比, 虽然植被面积扩大至 $6.7 \mathrm{hm}^{2}$, 但植物收割量却略有下降, 为 $104 \mathrm{t}$ (干重(表 3)). 这一方面是由于东 方香蒲在上一年人工高密度繁育情况下, 疯狂生长, 其群落内部甚至出现了发黑发臭的厌氧状态, 在 2003 年收割 过后, 其群落密度在自然状态下有所降低,生物量也相对减少; 另一方面, 由于荠草群落在 2003 年 7 月大面积感染 “锈病”,也是造成总生物量降低的重要因素.

表 3 岸带生态修复区水生植物生长及收获对氮磷的净化量

Tab. 3 The nutrient content removed by growing and being harvested of aquatic plant in the restoration zone

\begin{tabular}{|c|c|c|c|c|c|c|c|}
\hline \multirow{2}{*}{ 时间 } & \multirow{2}{*}{$\begin{array}{c}\text { 植被面积 } \\
\left(\mathrm{hm}^{2}\right)\end{array}$} & \multicolumn{3}{|c|}{ 水生植物总生长量 $(\mathrm{kg})$} & \multicolumn{3}{|c|}{ 水生植物收割输出量 ( kg) } \\
\hline & & 生物量 & 含氮 & 含磷 & 生物量 & 含氮 & 含磷 \\
\hline 2002 年 & 4.7 & 228000 & 2446 & 453 & 113000 & 1212 & 225 \\
\hline 2003 年 & 6.7 & 289000 & 3100 & 574 & 104000 & 1115 & 207 \\
\hline
\end{tabular}

\section{3 修复区内外水质变化}

修复区内 $\mathrm{COD}_{\mathrm{Cr}}$ 的年度变化趋势与 Chl. a 含量 (浮游植物、藻类生物量指标) 相似 ${ }^{[15]}$, 在 $3-6$ 月, 低于对照 
点,而在蓝藻水华大量爆发期间大幅度上升,远高于修复区外,但随即迅速下降,并低于修复区外. TN、TP 含量在 藻类爆发季节 $(9 、 10)$ 月份也出现了短期极高的峰值并迅速回落的现象, 这说明, 修复区在对藻类吸纳富集、分解 转化的过程中,水体中的有机质浓度和氮、磷含量都会明显升高,但随着藻类分解程度的加深, 大量的有机质都已 分解, 最终从水体中去除, 此后, 修复区内的污染物含量迅速降低, 直至各项水质指标普遍优于修复区外. 引起这 一现象的原因主要是由于藻类浓度的变化引起的, 这也证明了, 修复区不仅能够大量聚集、吸纳漂浮性蓝藻, 而且 能够通过分解转化这些蓝藻, 使其中的营养物质通过多种机制从水体中去除,达到净化水质的作用.

\section{4 结论}

滇池沿岸带生态修复对岸带底质环境的改善和内源污染的净化能力是极为显著的, 在 2002 年度, $4.7 \mathrm{hm}^{2}$ 的 生态修复区沉积物干重可以达到 $5617.91 \mathrm{t}$, 收获水生植物 $113 \mathrm{t}$ (干重), 通过沉积和植物收割打捞可去除氮 $6.95 \mathrm{t}$, 磷 $3.52 \mathrm{t}$; 可以作为湖泊内源污染净化的一项工程措施在滇池东北沿岸或类似重污染水体推广应用. 修复区强大 的污染净化能力与其中藻类的聚集、分解转化密切相关, 由此认为, 通过对藻类的收集处置, 利用其强大的吸收同 化作用,去除水体中的污染物质是完全可行的.

\section{5 参考文献}

[1] Wetzel R G. Limnology :lake and river ecosystems. 3rd edn. San Diego:Academic Press, 2001.

[2] 杨清心. 东太湖水生植被的生态功能及调节机制. 湖泊科学, 1998,10(1):67 - 72.

[3] Havens K E, Fukushima T. Nutrient dynamics and the eutrophication of shallow lakes-Kasumigaura (Japan), Donghu (PR China), and Okeechobee (USA). Environmental Pollution,2001,111: 263 - 272.

[4] 宋祥甫,邹国燕, 吴伟明等. 浮床水稻对富营养化水体中氮、磷的去除效果及规律研究. 环境科学学报, 1998, 18(6): 489 - 494.

[5] 戴全裕,蒋兴昌,汪耀斌等. 太湖人湖河道污染物控制生态工程模拟研究. 应用生态学报, 1995,6(2):201 -205 .

[6] 吴玉树,余国营. 根生沉水植物沮草. (Potamogeton crispus) 对滇池水体的净化作用. 环境科学学报, 1991,11 (4) :411 - 416.

[7] 吴玉树,李森林. 水生维管束植物对滇池水体的净化效应.生态学报,1988.8(4):347 - 353.

[8]王旭明,匡 晶.水芹菜对污水净化的研究. 农业环境保护, 1999,18(1):34-35.

[9] 李文朝. 富营养水体中常绿水生植被组建及净化效果研究. 中国环境科学, 1997,17(1):53-57.

[10] 吴振斌,邱东茹等. 水生植物对富营养水体水质净化作用研究. 武汉植物学研究,2001,19(4):299-303.

[11] 李文朝. 东太湖沉积物中氮的积累与水生植物沉积. 中国环境科学,1997,17(5):418-424.

[12] 李文朝. 东太湖水生植物的促淤效应与磷的沉积. 中国环境科学, 1997,18(3):9-13.

[13] 孙顺才等.太湖. 北京:海洋出版社,1993:23-120.

[14] 吴庆龙, 胡耀辉, 李文朝等. 东太湖沼泽化发展趋势及驱动因素分析. 环境科学学报. 2000,20(3):275 - 279 .

[15] 潘继征,李文朝,陈开宁. 滇池东北岸生态修复区的环境效应研究—-I. 抑藻效应研究. 湖泊科学, 2004, 16 (2) : 141 - 148 .

[16] 黄祥飞,陈伟民, 蔡启铭等. 湖泊生态调查观测与分析. 北京: 中国标准出版社, 2000 .

[17] 李文朝,陈开宁等. 东太湖水生植物生物质腐烂分解实验. 湖泊科学, 2001, 13(4):331-336. 